\title{
Surto de salmonelose pelo sorovar Dublin em bezerros no Maranhão ${ }^{1}$
}

\author{
Ana L.A. Marques², Sara V.D. Simões ${ }^{2 *}$, Felício Garino Jr.2, Lisanka A. Maia², Tatiane \\ R. da Silva ${ }^{2}$, Beatriz Riet-Correa ${ }^{2}$, Everton F. Lima² e Franklin Riet-Correa ${ }^{2}$
}

\begin{abstract}
Marques A.L.A.M., Simões S.V.D., Garino Jr F., Maia L.A., Silva T.R., Riet-Correa B.R., Lima E.F. \&, Riet-Correa F. 2013. [Outbreak of salmonellosis by serovar Dublin in calves in the State of Maranhão, Brazil.] Surto de salmonelose pelo sorovar Dublin em bezerros no Maranhão. Pesquisa Veterinária Brasileira 33(8):983-988. Hospital Veterinário, Centro de Saúde e Tecnologia Rural, Universidade Federal de Campina Grande, Patos, PB 58700-000, Brazil. E-mail: saravilar@bol.com.br

An outbreak of salmonellosis due to Salmonella enterica subsp. enterica sorovar Dublin is reported in calves in a farm in the municipality of Timon, state of Maranhão. From a total of 62 calves, 22 (35.5\%) were affected and 9 (40.9\%) died. Clinical signs were fever, depression, anorexia, and, in some cases, respiratory, neurological or enteric signs, or arthritis. The clinical manifestation period was hyperacute to subacute. Main gross lesions were enlarged liver and spleen, and presence of exudate in the cavities. Histologically, paratyphoid granuloma were seen in the liver, kidney, and spleen. Thrombosis and bacterial aggregates in blood vessels were observed in various organs. After the realization of the antibiogram the outbreak was controlled by adoption of appropriate antibiotic therapy combined with the correction of sanitary measures.
\end{abstract}

INDEX TERMS: Calves, infectious diseases, salmonellosis, semiarid region.

RESUMO.- Um surto de salmonelose em bezerros causado pela Salmonella enterica subsp. enterica sorovar Dublin é relatado em uma fazenda no município de Timon, Maranhão. De um total de 62 bezerros, $22(35,5 \%)$ adoeceram e destes nove $(40,9 \%)$ morreram. Os sinais clínicos incluíram febre, depressão, anorexia e, em alguns casos, sinais respiratórios, neurológicos, entéricos ou artrites, com curso clínico hiperagudo ou subagudo. As principais lesões macroscópicas foram hepatomegalia com áreas pálidas multifocais a coalescentes, esplenomegalia e líquido nas cavidades torácica e abdominal. Histologicamente foram observados granulomas paratifoides no fígado, rim e baço, além de trombos e agregados bacterianos em vasos sanguíneos de diversos órgãos. 0 surto foi controlado com a adoção de antibioticoterapia adequada aliada a correção de algumas medidas sanitárias na propriedade.

TERMOS DE INDEXAÇÃO: Bezerros, doenças infecciosas, salmonelose, semiárido.

\footnotetext{
${ }^{1}$ Recebido em 11 de março de 2013.

Aceito para publicação em 27 de junho de 2013.

${ }^{2}$ Hospital Veterinário, Centro de Saúde Tecnologia Rural (CSTR), Universidade Federal de Campina Grande (UFCG), Patos, PB 58700-000, Brasil. *Autor para correspondência: saravilar@bol.com.br
}

\section{INTRODUÇÃO}

Dentre os agentes envolvidos nas doenças dos bezerros as bactérias do gênero Salmonella se destacam por causarem grave doença clínica e por serem enteropatógenos cosmopolitas que acometem diversas espécies animais, inclusive a humana, sendo a salmonelose uma zoonose comum e economicamente importante (OIE 2010). Mais de 2500 sorovares são conhecidos, todos pertencentes a três espécies (S. enterica, S. bongori e S. subterranea), sendo as infecções de animais de sangue quente associadas aos sorovares de $S$. enterica subesp. enterica (Brenner et al. 2002).

Apesar de diversos sorovares estarem associados à infecção de bovinos, a salmonelose nessa espécie é causada predominantemente por Salmonella enterica subsp. enterica sorovar Thyphimurium e $S$. enterica subesp. enterica sorovar Dublin. Embora ambos causem doença entérica, diferentes manifestações clínicas podem ser observadas. 0 sorovar Thyphimurium é frequentemente associado a enterites que afetam bezerros jovens, causando diarreia aguda grave. 0 sorovar Dublin é mais relacionado a infecções sistêmicas em bezerros, geralmente não associadas à diarreia e, ocasionalmente, causa aborto em vacas prenhes (Anderson \& Blanchard 1989, Mohler et al. 2009, Carrique- Mas et al. 2010). 
O sorovar Dublin é considerado adaptado aos bovinos, sendo capaz de permanecer no rebanho em animais portadores. Esses portadores, que não demonstram sinais clínicos, são classificados em ativos, passivos ou latentes e excretam o agente no ambiente de maneira contínua, esporádica ou em condições de estresse, através das fezes e/ou leite. A presença de portadores no rebanho é um dos grandes entraves para o controle das infecções por este sorovar, pois estes atuam como fontes de infecção para os outros animais (Nielsen et al. 2004, Barros 2007).

A infecção acontece geralmente por contaminação ambiental ou alimentar. A principal via de transmissão é a fecal-oral, porém já foram relatadas infecções através das mucosas dos tratos respiratório superior e geniturinário, conjuntiva ocular, por via transplacentária e umbilical (Mohler et al. 2009).

No Brasil o estabelecimento da incidência da salmonelose é dificultado pelas diferentes condições de manejo e a escassez de recursos e infraestrutura para o diagnóstico laboratorial em diversas regiões (Pereira et al. 2004). Considerando que a salmonelose causa graves perdas econômicas e que o diagnóstico é importante para que medidas adequadas de tratamento e profilaxia sejam instituídas nos rebanhos, objetivou-se com este trabalho estudar um surto de salmonelose septicêmica em bezerros no estado do Maranhão e colaborar com a compreensão de aspectos epidemiológicos, clínicos e patológicos desta enfermidade no Nordeste do Brasil.

\section{MATERIAL E MÉTODOS}

O estudo foi realizado entre os meses de maio e setembro de 2012 em uma propriedade no Município de Timon, Maranhão. Dados epidemiológicos foram obtidos junto ao proprietário e tratadores durante visitas à fazenda. Os animais acometidos foram submetidos a exame clínico e coleta de material para realização de hemograma, pesquisa de hematozoário e exames bioquímicos. Necropsias foram realizadas em cinco animais e fragmentos de órgãos encaminhados para exames microbiológicos e histopatológicos no Hospital Veterinário da Universidade Federal de Campina Grande (UFCG), Campus de Patos, PB. Para a histopatologia o material foi fixado em formol tamponado a $10 \%$, incluído em parafina, cortado a $5 \mu \mathrm{m}$ de espessura e corado pela hematoxilina-eosina (HE). Para o exame microbiológico fragmentos do fígado de um animal, que morreu in extremis, foram refrigerados e posteriormente semeados em caldo $\mathrm{BHI}$, em placas contendo ágar EMB (Eosina azul de metileno) e ágar MacConkey e incubadas a $37^{\circ} \mathrm{C}$ por 24 horas em aerobiose. Através de provas bioquímicas (malonato, citrato de Simmons, uréia, gelatinase, lactose, vermelho de metila, Vouges-Prouskauer, motilidade, produção de indol e redução de nitrato) identificou-se o gênero Salmonella. A identificação da espécie baseou-se no Bergey`s Manual of Microbiology (Krieg \& Holt 1984). Provas para identificação do sorovar foram realizadas no Laboratório de Enterobactérias do Departamento de Bacteriologia, do Centro de Referência Nacional de Cólera e outras Enteroinfecções Bacterianas da Fundação Instituto Oswaldo Cruz (Fiocruz, Rio de Janeiro).

A susceptibilidade in vitro aos antimicrobianos foi avaliada pela técnica de disco difusão em placas contendo meio ágar Mueller Hinton de acordo com o CLSI (2005). Foram utilizados os seguintes antimicrobianos: ampicilina $30 \mathrm{mcg}$, tetraciclina $30 \mathrm{mcg}$, norfloxacina $10 \mathrm{mcg}$, cefoxitina $30 \mathrm{mcg}$, ceftiofur $30 \mathrm{mcg}$, cefalexi- na $30 \mathrm{mcg}$, gentamicina $10 \mathrm{mcg}$, polimixina $300 \mathrm{UI}$, cefotaxina 30 $\mathrm{mcg}$, aztreonam $30 \mathrm{mcg}$, amoxilina $30 \mathrm{mcg}$, enrofloxacina $5 \mathrm{mcg}$ (Sensidisc - Cecon $囚$ ). A interpretação dos resultados também foi realizada de acordo com o CLSI (2005).

\section{RESULTADOS}

\section{Dados anamnésicos e epidemiológicos}

0 rebanho era composto por 165 animais mestiços da raça holandesa, gir e guzerá e dois reprodutores, criados em regime semi-intensivo e utilizados para exploração de leite. De um total de 62 bezerros, 22 (35,5\%) adoeceram, e destes, nove $(40,9 \%)$ morreram. A faixa etária dos animais acometidos variou de 13 dias a 15 meses e os óbitos ocorreram entre os mais jovens (três animais no primeiro mês de vida, dois no segundo e quatro no terceiro). A enfermidade acometeu bezerros anteriormente saudáveis ou com histórico de onfalite, baixo peso ao nascimento ou nascidos de mães que durante a gestação apresentaram sinais inespecíficos de enfermidades e foram tratadas de forma sintomática pelo proprietário. A introdução de bovinos (novilhas, vacas e reprodutores) de outras regiões era uma prática relativamente frequente na propriedade, pois o plantel estava em formação.

Na propriedade estava sendo implantado o sistema de pastejo rotacionado. Entre 40 e 45 bezerros de diferentes faixas etárias tinham acesso a piquetes irrigados de capim estrela africana (Cynodon nlemfuensis) medindo $836,5 \mathrm{~m}^{2}$, havendo troca de piquete a cada 24 horas. 0 fornecimento de água era feito em cochos de borracha que eventualmente eram vistos vazios, pois o sistema de abastecimento não era automatizado. Nos piquetes era utilizada adubação química e orgânica. 0 esterco era na maioria das vezes proveniente de esterqueira, mas também se utilizava esterco fresco proveniente dos currais.

Os bezerros tinham contato com as vacas apenas no momento da ordenha, que era realizada com o bezerro ao pé. Antes desta eram mantidos em bezerreiro coletivo, higienizado uma vez ao dia. Após a ordenha tinham acesso, também em instalação coletiva, a ração concentrada à base de milho, farelo de soja e núcleo mineral na quantidade de $1 \%$ do peso vivo. 0 pernoite ocorria em curral a céu aberto com boa higienização.

Na propriedade não havia área isolada para os animais doentes ou piquetes maternidade e a parição normalmente ocorria a campo. Após o parto os bezerros permaneciam com as mães por aproximadamente três semanas em currais nas proximidades do centro de manejo e a ingestão de colostro era feita de forma natural. 0 corte e a desinfecção do umbigo faziam parte das práticas sanitárias, porém esporadicamente ocorriam casos de infecção umbilical.

Na propriedade havia uma grande quantidade de animais silvestres como capivaras (Hydrochoerus hydrochaeris) e garças (Bubulcus ibis). 0 proprietário associou o aumento do número de capivaras à ausência de predadores e a existência de ambiente propício para a sua permanência e reprodução.

\section{Sinais clínicos}

Apatia, febre $\left(41,1-42,1^{\circ} \mathrm{C}\right)$, diminuição do apetite, aumento de volume do abdome ventral, edema nas pálpebras 
superiores e polidipsia foram os sinais clínicos iniciais e comuns a maioria dos animais que adoeceram. Alguns animais apresentaram palidez de mucosa e icterícia. Logo após o início dos sinais os bezerros eram tratados com antimicrobianos (tetraciclina ou enrofloxacina), antitóxicos, complexos vitamínicos e fluidoterapia endovenosa. Mesmo sendo medicados, três morreram nas primeiras 24 horas. Outro bezerro (Fig.1A) teve rápido agravamento do quadro clínico inicial e apresentou dispneia, tremores musculares, andar em círculos, movimentos mastigatórios, sialorréia, blefaroespasmo, ausência de reflexo pupilar, decúbito e morte 48 horas após o início dos sinais clínicos. Alguns animais apresentaram remissão parcial dos sinais após medicação inicial, porém posteriormente apresentaram secreção nasal seromucosa a mucopurulenta, tosse improdutiva, fezes diarreicas e fétidas. Dois animais apresentaram artrite e um outro edema nos membros anteriores.
No hemograma, realizado em cinco animais, observou-se que em três havia redução no número de hemácias (3,69-4,1 hemácias x10 $/ \mu \mathrm{L})$ e do volume globular (21$22 \%)$. Em quatro animais não foram visualizados hemoparasitas no esfregaço sanguíneo e em um havia poucas células parasitadas com Anaplasma marginale, o que não caracterizava a infecção. O leucograma de um animal demonstrou leucocitose $\left(17.600 / \mathrm{mm}^{3}\right)$ por neutrofilia (9.328) e desvio à esquerda. Em outro, com quadro agudo, observou-se leucopenia $(4000 / \mu \mathrm{L})$ por neutropenia $\left(600 / \mathrm{mm}^{3}\right)$ e monocitose relativa (14\%). A monocitose foi evidenciada em mais dois animais $\left(1.254 / \mathrm{mm}^{3}\right.$ e $1.600 /$ $\mathrm{mm}^{3}$ ). No leucograma de um animal com curso prolongado e aparentemente recidivante não foram encontradas alterações. Os constituintes bioquímicos séricos de animais acometidos durante as visitas estão demonstrados no Quadro 1.

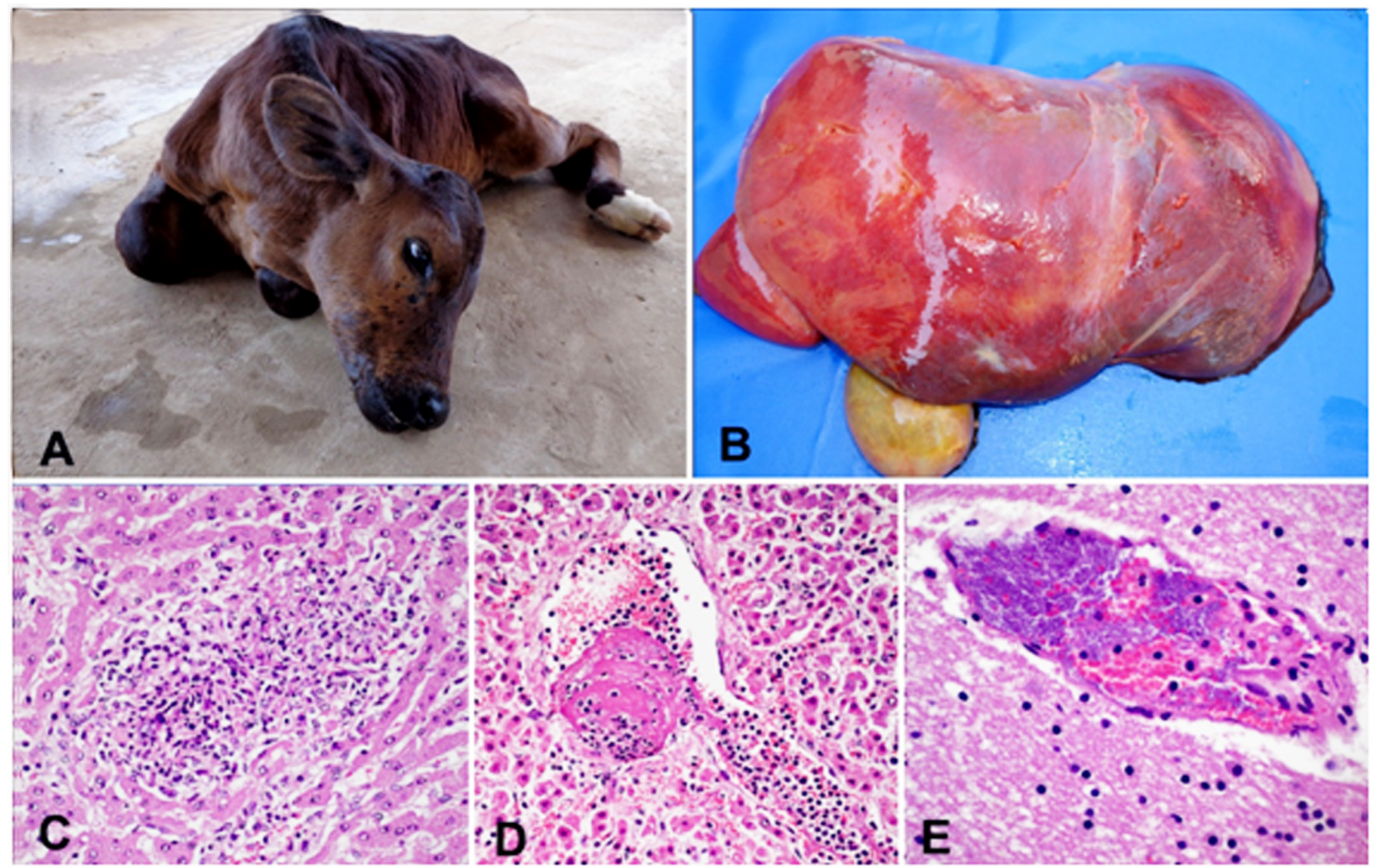

Fig.1. (A) Bezerro em decúbito esternal com a cabeça apoiada no solo, demonstrando marcada depressão. (B) Fígado aumentado de volume com áreas pálidas multifocais a coalescentes distribuídas por toda superfície da cápsula de Glisson. Vesícula biliar distendida e edemaciada. (C) Granuloma paratifoide no tecido hepático (D) Trombo intravascular em um vaso hepático. No detalhe, trombo intravascular com a presença de agregados bacterianos na região encefálica. HE, obj.20x

Quadro 1. Constituintes bioquímicos séricos de bezerros acometidos por salmonelose septicêmica em propriedade rural no Município de Timon, Maranhão

\begin{tabular}{ccccccc}
\hline Animal & $\begin{array}{c}\text { GGT } \\
\text { (VR - 6,1-17,4 U/L) }\end{array}$ & $\begin{array}{c}\text { AST } \\
(78-132 \mathrm{U} / \mathrm{L})\end{array}$ & $\begin{array}{c}\text { PT } \\
(6,74-7,46 \mathrm{~g} / \mathrm{dL})\end{array}$ & $\begin{array}{c}\text { Albumina } \\
(3,03-3,55 \mathrm{~g} / \mathrm{dL})\end{array}$ & $\begin{array}{c}\text { Uréia } \\
(42,8-64,2 \mathrm{mg} / \mathrm{dL})\end{array}$ & $\begin{array}{c}\text { Creatinina } \\
(1,0-2,0 \mathrm{mg} / \mathrm{dL})\end{array}$ \\
\hline 1 & 60,2 & 30 & 6,6 & 2,4 & 37 & 1,7 \\
2 & 45 & 47 & 6,8 & 2,7 & 15 & 0,8 \\
3 & 22 & 57 & 5,3 & 3,1 & 44 & 1,2 \\
4 & 29,9 & 36 & 8,7 & 1,9 & 24 & 0,83
\end{tabular}

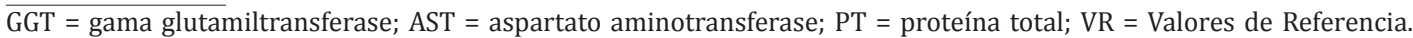
Fonte: Kaneko et al. (2008). 


\section{Patologia}

Os principais achados macroscópicos foram identificados no fígado que estava aumentado de volume, difusamente alaranjado e com áreas pálidas multifocais a coalescentes distribuídas por toda superfície da cápsula de Glisson. A vesícula biliar estava distendida e edemaciada (Fig.1B). 0 baço estava aumentado de tamanho. Um dos animais apresentava líquido amarelado nas cavidades abdominal e torácica e discreto edema na região subcutânea e perirrenal. Os pulmões estavam avermelhados e não colapsados, com impressão das costelas na superfície pleural. Áreas de consolidação foram identificadas em quatro animais e em um destes também havia grave enfisema pulmonar.

Histologicamente o fígado apresentava granulomas paratifoides (Fig.1C) multifocais a coalescentes, variando de discreto a acentuado, constituídos por infiltrado inflamatório de macrófagos, linfócitos e raros neutrófilos, associados a áreas de necrose de hepatócitos, além de infiltrado mononuclear periportal. Trombos foram ocasionalmente observados (Fig.1D). Granulomas paratifoides foram também observados no rim. Em um dos animais além das lesões descritas acima, havia agregados de bactérias associadas aos granulomas paratifoides. Havia células inflamatórias distendendo os sinusoides. Infiltrado inflamatório semelhante e com agregados bacterianos foi observado dentro de vasos sanguíneos, algumas vezes formando trombos, nos rins, baço, linfonodo pré-escapular, córtex cerebral (Fig.1D, no detalhe) e leptomeninges. Havia também agregados bacterianos aleatórios no neurópilo do córtex cerebral. No baço foram observadas áreas multifocais a coalescentes de necrose e múltiplos granulomas paratifoides. Alguns linfonodos tinham necrose de centro germinativo, rarefação da zona paracortical e diminuição da celularidade, além de congestão acentuada. Depleção linfóide foi vista no baço e linfonodos. No intestino de um animal foi observado ileite necrótica multifocal a coalescente discreta às vezes associada a agregados bacterianos e necrose de centros germinativos.

\section{Microbiologia}

Colônias puras não fermentadoras de lactose com 2-3mm de diâmetro foram observadas nos meios EMB e ágar MacConkey e através das provas bioquímicas foi possível identificá-las como pertencentes ao gênero Salmonella sp. Pela detecção de antígenos somáticos e flagelares o isolado foi identificado como S. enterica subesp. enterica sorovar Dublin.

0 antibiograma revelou resistência à tetraciclina e polimixina e sensibilidade aos grupos de quinolonas (norfloxacin, enrofloxacina), $\beta$-lactâmicos (cefalexina, cefotaxina, cefoxitina, aztreonam, ampicilina, amoxilina) e aminoglicosídeos (gentamicina). Apenas um $\beta$-lactâmico (ceftiofur) apresentou sensibilidade intermediária, os demais foram 100\% sensíveis.

\section{Controle}

Para o controle da enfermidade os animais doentes passaram a ser tratados com enrofloxacina em substituição à tetraciclina, pois foi identificada resistência da Salmonella isolada a esta droga. Com a adequada terapia antimicrobiana observou-se redução dos sinais clínicos em muitos animais nas primeiras $24 \mathrm{~h}$ de tratamento. 0 proprietário foi orientado a mensurar a temperatura retal dos animais sempre que os bezerros apresentassem qualquer mudança no comportamento. Esta medida assegurou intervenções precoces e reduziu a gravidade dos casos e a consequente letalidade, pois a elevação da temperatura muitas vezes ocorria antes da manifestação dos demais sinais clínicos. Além disso, foi recomendado que a higienização das áreas dos bezerros fosse realizada com maior frequência e houvesse uma oferta permanente de água para evitar estresse hídrico. A atenção com a alimentação dos bezerros e ingestão de colostro foi intensificada e foram dadas orientações no sentido de evitar a utilização de esterco fresco na capineira.

\section{DISCUSSÃO E CONCLUSÕES}

A presença de culturas puras de Salmonella sp. nos exames microbiológicos e de granulomas paratifoides no fígado, baço e rim dos animais necropsiados comprovaram a ocorrência da doença no rebanho. A observação dos infiltrados inflamatórios, associados a áreas de necrose, com agregados bacterianos nos órgãos e em vasos sanguíneos são aspectos característicos de bacteremia. De acordo com Brown et al. (2007) a observação microscópica de granulomas paratifoides em diversos órgãos provavelmente representa uma resposta celular imunomediada à bacteremia embólica. Sanches et al. (1999) descrevendo surto de salmonelose por S. enterica subesp. enterica sorovar Dublin observaram também infiltrado neutrofílico e macrofágico, vasculite com necrose endotelial e trombos no fígado e baço. A hepato e esplenomegalia e a congestão pulmonar são, também, achados consistentes e fortemente sugestivos de salmonelose septicêmica (Barros 2007, Blanchard 2012). A enterite discreta observada em um animal, que não apresentou diarreia, é comum nas infecções pelo sorovar Dublin (Fossler et al. 2005).

As manifestações clínicas observadas foram condizentes com o sorovar identificado, pois de acordo com Rebhun (2000) S. enterica subsp. enterica sorovar Dublin pode apresentar sinais intestinais, septicêmicos ou respiratórios. No entanto, os sinais clínicos iniciais não foram suficientes para o diagnóstico da enfermidade, pois eram semelhantes aos observados em outras afecções de animais jovens como as integrantes do complexo das doenças respiratórias, a anaplasmose e outros patógenos entéricos. Ekperigin \& Nagaraja (1998) ressaltaram que a história do rebanho, os achados clínicos e de necropsia apenas levantam a suspeita da enfermidade e que para o diagnóstico definitivo é necessário o isolamento e a caracterização do agente.

Vários aspectos já considerados importantes na epidemiologia desta enfermidade foram observados na propriedade, como introdução de novos animais (Houston et al. 2002), utilização de esterco nos piquetes (Warnick et al. 2001), estresse hídrico e modificações no manejo (Nielsen 2003), presença de animais e aves silvestres (Evans 1996), manutenção de animais de diferentes idades no mesmo ambiente e aumento no número de animais (Fossler et al. 
2005). Esses aspectos dificultaram a identificação da fonte de infecção ou o principal fator desencadeante do surto. Porém, considerou-se que a utilização de esterco fresco nos piquetes dos bezerros, a introdução de vacas no rebanho e a manutenção de animais no pós-parto imediato em currais próximos ou mesmo compartilhando as áreas disponibilizadas para os bezerros podem ter sido determinantes para a ocorrência do surto. A ausência de um piquete exclusivo para animais enfermos pode ter contribuído para a disseminação da doença e o longo período de duração do surto, pois as fezes, secreções nasais e a saliva dos animais infectados (Anderson \& Blanchard 1989) contêm grandes quantidades do microorganismo e são capazes de contaminar o ambiente e os outros animais. De acordo com McGuirk \& Peek (2003) os surtos de salmonelose comumente duram muitos meses. Surtos mais prolongados podem ser decorrentes da persistência do agente no meio ambiente, persistência dos fatores de risco, presença de portadores ou reinfecção de animais susceptíveis.

A imaturidade do sistema imunológico dos animais mais jovens provavelmente esteve associada ao fato dos casos mais graves e o maior número de mortes terem sido registrados nos animais de até três meses. Segundo Nielsen (2003) a idade dos animais é muito relevante para o desenvolvimento dos sinais clínicos na salmonelose. Bezerros com até três meses são incapazes de produzir uma resposta imune rápida e eficaz contra a infecção. Os mais jovens, com idade inferior a quatorze dias, apresentam certa proteção pelos anticorpos adquiridos através do colostro, sendo os bezerros entre quatorze dias e três meses mais susceptíveis à infecção e consequentemente ao aparecimento dos sinais clínicos.

A variação observada no curso clínico da enfermidade e na sintomatologia apresentada pelos animais, que incluiu sinais septicêmicos, respiratórios, neurológicos, entéricos e artrites, é uma característica da infecção por S. enterica subesp. enterica sorovar Dublin e pode confundir os veterinários não familiarizados com a doença. A septicemia causada pelo sorovar Dublin, às vezes, é a única manifestação da doença (Fossler et al. 2005). A diarreia, mais frequentemente observada na infecção pelos sorovares Newport ou Thyphimurium, pode não ser o sinal principal nas infecções agudas pelo sorovar Dublin, porém, a secreção de enterotoxinas pela bactéria pode causá-la, independente do dano à mucosa intestinal (Rebhun 2000). Para Mee (1995) o sorovar Dublin é mais invasivo que o Thyphimurium podendo ainda causar meningoencefalite, artrite séptica e necrose gangrenosa das extremidades distais. De acordo com Wray \& Sojka (1977) habitualmente os animais ficam septicêmicos, apresentando sinais respiratórios e febre.

Os achados variáveis do leucograma, pois foram observados animais com leucocitose, leucopenia e contagens leucocíticas normais estão de acordo com as informações da literatura. 0 leucograma de bezerros infectados pelo sorovar Dublin fica extremamente variável e reflete a duração da infecção. Animais com infecção aguda podem apresentar neutropenia e com desvio à esquerda, severamente neutropênicos ou com contagens leucocíticas normais. Neutrofilia suave a moderada é observada em casos subagudos ou crônicos. A elevação da atividade sérica de GGT pode estar associada às lesões hepáticas observadas. A hipoalbuminemia observada em alguns casos pode ser associada à perda proteica no interior do intestino pelo aumento da permeabilidade e a má absorção intestinal (Rebhum 2000, Smith 2006).

A realização do antibiograma e a identificação precoce dos casos mediante a determinação da temperatura retal foi extremamente importante para o controle do surto assim como a correção de aspectos do manejo que poderiam estar ocasionando estresse ou favorecendo a exposição dos animais a fontes de infecção. Ribeiro et al. (2010) ao caracterizarem os sorovares de Salmonella isolados em diferentes afecções de animais domésticos, preconizaram que a presença de linhagens multi resistentes no estudo reforça a necessidade da realização de testes de sensibilidade microbiana previamente à instituição de protocolos terapêuticos com vistas a maximizar a efetividade dos fármacos.

Apesar do surto ter sido controlado deve-se considerar que a eliminação de Salmonella enterica subsp. enterica sorovar Dublin de um ambiente já contaminado é difícil, pois este sorovar tem a característica peculiar de adaptar-se ao hospedeiro após a recuperação clínica e continuar sendo disseminado. Dessa maneira, a identificação e eliminação dos animais portadores são medidas que podem ser necessárias para evitar que a enfermidade torne-se endêmica na propriedade.

Agradecimentos.- Ao Dr. Roberto Dantas Vilar Sobrinho e Sra. Darlene Fernandes Tomaz Dantas pela contribuição durante as visitas e obtenção de dados para a realização deste trabalho e a Dra. Lucilene Santos pela disponibilidade e contribuição durante as coletas e realização de exames.

\section{REFERÊNCIAS}

Anderson M. \& Blanchard P. 1989. The clinical syndromes caused by Salmonella infection. Vet. Med. 84:816-819.

Barros C.S.L. 2007. Salmonelose, p.416-425. In: Riet-Correa F., Schild A.L., Lemos R.A.A. \& Borges J.R.J. (Eds), Doenças de Ruminantes e Equideos. Vol.1. 3 a ed. Pallotti, Santa Maria.

Blanchard P.C. 2012. Diagnostics of dairy and beef cattle diarrhea. Vet. Clin. North Am., Food Anim. Pract. 28:443-464.

Brenner F.W., Villar R.G., Angulo F.J., Tauxe R. \& Swaminathan B. 2002. Salmonella nomenclature. J. Clin. Microbiol. 38:2465-2467.

Brown C.C., Baker D.C. \& Baker I.K. 2007. Alimentary system, p.193-204. In: Maxie M.G. (Ed.), Jubb, Kennedy and Palmer's Pathology of Domestic Animals. Vol.2. $5^{\text {th }}$ ed. Saunders Elsevier, Philadelphia.

Carrique-Mas J.J., Willmington J.A., Papadopoulou C., Watson E.N. \& Davies R.H. 2010. Salmonella infection in cattle in Great Britain, 2003 to 2008. Vet. Rec. 167:560-565.

CLSI 2005. Performance standards for antimicrobial susceptibility testing. $15^{\text {th }}$ Informational Supplement. Document M100-S15. Clinical and Laboratory Standards Institute, Pennsylvania, USA.

Ekperigin H.E. \& Nagaraja K.V. 1998. Salmonella. Vet. Clin. North Am., Food Anim. Pract. 14(1):17-29.

Evans S.J. 1996. A case control of study of multiple-resistant S. thyphimurium DT1 04 infection of cattle in Great Britain. Cattle Pract. 4:259-263.

Fossler C.P., Wells S.J., Kaneene J.B., Ruegg P.L., Warnick L.D. \& Eberly L.E. 2005. Cattle and environmental sample-level factors associated with the presence of Salmonella in a multi-state study of conventional and organic dairy farms. Prev. Vet. Med. 67(1):39-53.

Houston C.L.,Wittum T.E., Love B.C. \& Keen J.E. 2002. Prevalence of fe- 
cal shedding of Salmonella spp. in dairy herds. J. Am. Vet. Med. Assoc. 220:645-649.

Kaneko J.J., Harvey J.W. \& Bruss M.L. 2008. Clinical Biochemistry of Domestic Animals. $6^{\text {th }}$ ed. Academic, San Diego. 916p.

Krieg N.R. \& Holt J.G. 1984. Bergey's Manual of Systematic Bacteriology. Williams and Wilkins, London. 984p.

McGuirk S.M. \& Peek S. 2003. Salmonellosis in cattle: a review. $36^{\text {th }}$ Annual Conference of the American Association of Bovine Practitioners. Columbus, $0 H$, p.15-17.

Mee J.F. 1995. Terminal gangrene andostitis in calves attributed to Salmonella Dublin infection. Irish Vet. J. 48:22-28.

Mohler V.L., Izzo M.M. \& House J.K. 2009. Salmonella in calves. Vet. Clin. Food Anim. 25:37-54.

Nielsen L.R. 2003. Salmonella Dublin in dairy cattle: use of diagnostic tests for investigation of risk factors and infection dynamics. PHD thesis, Department of Animal Science and Animal Health, Royal Veterinary and Agricultural University, Denmark. 219p.

Nielsen L.R., Schukken Y.H., Grohn Y.T. \& Ersboll A.K. 2004. Salmonella Dublin infection in dairy cattle: risk factors for becoming a carrier. Prev. Vet. Med. 65:47-62.

OIE 2010. Salmonellosis: terrestrial manual 2010. Chapter 2.9.9. Office Int. Epizooties, Paris. 19p.
Pereira R.N., Ávila F.A. \& Fernandes S.A. 2004. Estudo do perfil epidemiológico da salmonelose em bezerros e da sensibilidade a antimicrobianos na região de Ribeirão Preto/SP, Brasil. Ars Vet. 20(1):62-66.

Rebhun W.C. 2000. Doenças infecciosas do trato intestinal: salmonelose, p.205-210. In: Ibid. (Ed.), Doenças do Gado Leiteiro. Roca, São Paulo.

Ribeiro M.G., Fernandes M.C., Paes A.C., Siqueira A.K., Pinto J.P.A.N. \& Borges A.S. 2010. Caracterização de sorotipos em linhagens do gênero Salmonella isoladas de diferentes afecções em animais domésticos. Pesq. Vet. Bras. 30(2):155-160.

Sanches A.W.D., Ecco R., Langohr I.M. \& Barros C.S.L. 1999. Surto de salmonelose em bovinos. Anais 9o Encontro Nacional de Patologia Veterinária, Belo Horizonte, MG, p.22.

Smith B.P. 2006. Salmonelose em ruminantes, p.775-779. In: Ibid. (Ed.), Medicina Interna de Grandes Animais. 3ª ed. Editora Manole, São Paulo.

Taxonomy.Database.2013. Disponível em: <.http://www.ncbi.nlm.nih. gov/Taxonomy/Browser/wwwtax.cgi?mode=Undef\&id=590\&lvl=3\&ke $\mathrm{ep}=1 \&$ srchmode $=1 \&$ unlock $>$ Acesso em 7 mai. 2013

Warnick L.D., Crofton L.M., Pelzer K.D. \& Hawkins M.J. 2001. Risk factors for clinical salmonellosis in Virginia, USA cattle herds. Prev. Vet. Med. 49:259-275.

Wray C. \& Sojka W.J. 1977. Bovine salmonellosis. J. Dairy Res. 44:383425. 